\title{
Treatment of Oily Wastewater Using Composite Flocculant of Polysilicate Ferro-Aluminum Sulfate - Rectorite
}

\author{
Shi-Qian Li, Pei-Jiang Zhou*, Ling Ding, Kai Feng \\ Department of Environmental science, School of Resource and Environmental Science, Hubei Biomass-Resource \\ Chemistry and Environmental Biotechnology Key Laboratory, Wuhan University, Wuhan, China. \\ E-mail:zhoupj@whu.edu.cn
}

\begin{abstract}
In this study, a novel flocculant was prepared by an inorganic polymetric flocculant (IPF) - polysilicate ferroaluminum sulfate (PSFA) and rectorite (REC). The structure of the PSFA-REC composite was characterized by Fourier transform infrared (FT-IR) spectroscopy and X-ray diffraction (XRD), in order to determine the optimal temperature. The flocculation test was made at $25^{\circ} \mathrm{C}, 45^{\circ} \mathrm{C}$ and $65^{\circ} \mathrm{C}$, the results indicated that when the temperature was $65^{\circ} \mathrm{C}$, the removal efficiency of the oil and COD was the best, which was $87.2 \%$ and $92.6 \%$ respectively. Then by comparisons among rectorite (REC), PSFA and the composite PSFA-REC at the temperature of $65^{\circ} \mathrm{C}$ and the optimal dosage of $11 \mathrm{mg} / \mathrm{L}$, the composite PSFA-REC showed better flocculation performance than flocculant REC and PSFA alone.
\end{abstract}

Keyword: Polysilicate Ferro-aluminum Sulfate, Rectorite, Flocculation, Oily Wastewater

\section{Introduction}

Effluent from iron industries cause great environmental pollution,. China, being the biggest iron producing country, inevitably discharges large volume of oily wastewater. This kind of oily wastewater, in which oil presents in emulsified form, is harmful to the aquatic environment [1]. Once a layer of oil emulsion forms on the water surface, it will prevent the containing pollutants from being absorbed to the water organisms and becoming incorporated into sediments. Even very low oil concentration can imperil human health through biological enrichment and biomagnifications, therefore, the treatment of oily wastewater raises great concern and becomes a long-term challenge both at home and abroad. In order to meet up-to-date strict, many technologies have been developed and applied in the iron industry in the past years, such as flotation [2], adsorption [3], biochemical [4], membrane separation process [5] and so on. However, in view of high running costs and chemical consumption as well as unstable effluent quail- ty, these technologies cannot be ultimately applied on industryscale [6].

WISCO (Wuhan Iron \& Steel Corporation), where we take the oily wastewater samples, adopted the combined process of sedimentation, contact oxidation and precipitation to treat oily emulsion, the flow chart is illustrated in
Figure 1. Even after some treating process, effluent $\mathrm{COD}_{\mathrm{Cr}}$ remained between $300 \mathrm{mg} / \mathrm{L}$ and $500 \mathrm{mg} / \mathrm{L}$, which still cannot satisfy Chinese Iron and Steel Industrial Water Pollutant Discharge Standards. Therefore, post-treatment of the oily emulsion is indispensable. Generally, the post-treatment technologies such as coagulation [6-9], activated carbon absorption [10,11], and flocculation are used to treat oily wastewater before its entering the sewage systems. But this kind of "charge patch" mechanism brings about many difficulties and results in extensive substitution of the materials. At present, flocculation techniques are widely used in processing oily wastewater, and many commercially available materials are used as flocculants, but development and improvement of flocculants' efficiency still remain very limited.

Rectorite (REC) is a particular clay mineral. It is a regular interstratified clay mineral with alternate pairs of a non-expansible dioctahedral mica-like layer and an expansible dioctahedral smectite-like layer in a 1:1 ratio. The interlayer cations of montmorillonite-like layers can be exchanged easily by either organic or inorganic cations, and therefore rectorite has water-swelling property [12]. Because of its good hydrophilicity and adsorption capability as well as colloid in the water, rectorite is often used for adsorption of heavy metal ions, decolorization and dephosphorization of organic waste- 

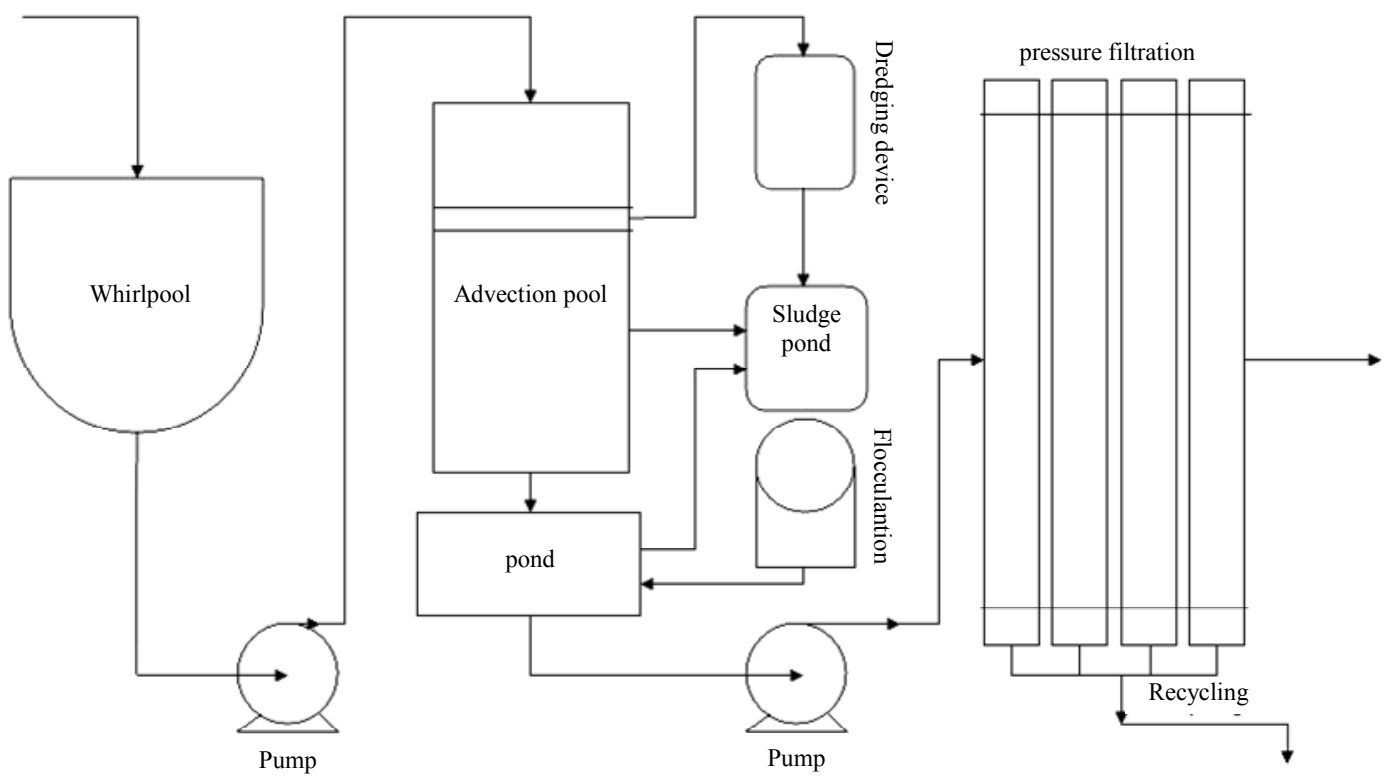

Figure 1. Schematic diagram of coagulation and plate-frame pressure filtration procedure in Wuhan Iron \& Steel Corporation wastewater reservoir.

Table 1. The Properties of Wastewater from Wuhan Iron \& Steel Corporation wastewater reservoir.

\begin{tabular}{cc}
\hline Parameter & Characteristic value $^{\mathrm{a}}$ \\
\hline $\mathrm{COD}_{\mathrm{Cr}}$ & $300-500$ \\
Oily content & 32 \\
$\mathrm{pH}$ & $8.3-8.6$ \\
Total alkalinity & 86 \\
Total iron & $1-5$ \\
\hline
\end{tabular}

${ }^{\mathrm{a}}$ All values are in $\mathrm{mg} / \mathrm{L}$ except $\mathrm{pH}$.

water containing ammonia nitrogen. Although it has certain role and advantages in wastewater treatment, its poor dispersion and suspension in water greatly restricted its application. For this reason, more and more scholars focus on modified rectorite to improve its properties of dispersion, suspension and adsorption. The exchangeable cations of rectorite are helpful to introduce inorganic and organic polymeric cations into the layer to prepare pillared compounds with large surface area and interlayer distance. After calcination, the loss of interlayer water could open its channel, enlarging surface area and improving adsorption capacity.

There are many reports on the use of inorganic polymeric flocculants (IPFs) in water or oily wastewater treatment. However, few reports have been found on the use of PSFA-REC composite flocculant in oily wastewater treatment. The objective of this research was to investigate the efficiency of flocculation process for the removal of oil, COD and the majority of organic matters in wastewater from advection pool using a new
flocculant-PSFA-REC. The comparison of flocculation performance between PSFA-REC and other flocculants such as polysilicate aluminum sulfate and rectorite was also carried out [13].

In this paper, PSFA-modified rectorite was used in wastewater treatment, oily wastewater was taken from the spray water system of the fourth branch factory in Wuhan Iron and Steel factory, the influence of the on-site wastewater temperature and flocculant dosage on the removal of oil and Chemical Oxygen Demand (COD) were discussed, and therefore obtaining the best process parameters of oily wastewater treatment.

\section{Materials and Methods}

\subsection{Materials}

The PSFA was prepared using $\mathrm{Na}_{2} \mathrm{SiO}_{3} \cdot 9 \mathrm{H}_{2} \mathrm{O}\left(\mathrm{M}_{\mathrm{W}}\right.$ 284.22), $\mathrm{FeSO}_{4}\left(\mathrm{M}_{\mathrm{W}} 278.02\right)$ and $\mathrm{Al}_{2}\left(\mathrm{SO}_{4}\right)_{3} \cdot 18 \mathrm{H}_{2} \mathrm{O}\left(\mathrm{M}_{\mathrm{W}}\right.$ 666.41), sulfuric acid, which were purchased from 
Shanghai Chemical Co, China, Calcium rectories $\left(\mathrm{Ca}^{2+}\right.$ -REC) refined from the clay minerals was provided by Hubei Mingliu Inc. Co. (Wuhan, China).

\subsection{Wastewater Samples}

The oily wastewater used in the experiment was obtained from Wuhan Iron \& Steel Corporation wastewater reservoir (Hubei Province, China), and the samples were the outlet water from one cold rolling mill which had been pretreated by chemical technologies, the main characteristics of the oily effluent and the discharge standards are shown in Table 1. It had high COD, oil content, and $\mathrm{pH}$ values.

\subsection{Preparation of Flocculant PSFA-Rectorite}

The flocculant used in the experiment was prepared in the following two steps.

\subsubsection{Preparation of PSFA}

Firstly, $1.7 \mathrm{~g}$ sodium silicates, $99.96 \mathrm{~g}$ aluminum sulfate and $27.80 \mathrm{~g}$ ferrous sulfate were mixed in a glass reactor (1 L); secondly, $230 \mathrm{~mL} 98 \mathrm{wt} \% \%$ sulfuric acid was added to the reactor, then $230 \mathrm{~mL}$ tap water was slowly poured into the reactor while stirring and the solution was stirred for a few minutes; finally, the solution was agitated for $1.5 \mathrm{~h}$ to get the final flocculant PSFA. The flocculant was solid and white or yellow in colour, and its property does not change for at least 3 months. In practical coagulation experiments, $20 \mathrm{wt} \%$ PSFA stock solution was prepared with tap water (density: $1.0866 \mathrm{~g} / \mathrm{mL}, \mathrm{pH}$ : 0.41). $\mathrm{Al}_{2}\left(\mathrm{SO}_{4}\right)_{3}$ used as a comparison in this study was dissolved in tap water to make a $20 \mathrm{wt} . \%$ coagulant solution (density: $1.1238 \mathrm{~g} / \mathrm{mL}, \mathrm{pH}: 2.51$ ) [13].

\subsubsection{Preparation of the Composite PSFA-Rectorite}

Meanwhile, the PSFA and rectorite were used as flocculants to make comparisons with composites of the two flocculants, respectively. Firstly, $100 \mathrm{~mL}$ distilled water was added into a $500 \mathrm{~mL}$ round-bottom flask with certain dosage of rectorite to make a suspension, under $50^{\circ} \mathrm{C}$ water bath and stirring conditions, the corresponding dosage of PSFA solution was dropped into the solution. After a time, the reaction was stopped and the solution was cooled at room temperature. Then centrifugation was used to separate the solution, the sediment was dried. Finally, the dry form of sediment was ground to powder.

\subsection{Characterization of the PSFA-Rectorite}

Infrared spectra was obtained by FTIR spectroscopy usi- ng a Nicolet 470 FTIR spectrophotometer and potassium bromide pellets at room temperature.

FTIR spectroscopy was conducted on an FTIR spectrometer (Nicolet 5 DXB, Nicolet Biomedical Inc., Madison, WI) in the range between 4000 and $400 \mathrm{~cm}^{-1}$, with a resolution of $4 \mathrm{~cm}^{-1} .32$ scans at a resolution of 4 $\mathrm{cm}^{-1}$ were averaged and referenced against air. All powder samples were compressed into potassium bromide disks for the FTIR measurement.

XRD was performed using a diffractometer type D/max-rA (Tokyo, Japan) with $\mathrm{Ni}$ target and $\mathrm{K} \alpha$ radiation $(\lambda=0.154 \mathrm{~nm})$ at $50 \mathrm{kV}$ and $100 \mathrm{~mA}$. The scanning rate was $0.2 \% \mathrm{~min}$ and the scanning scope of $2 \theta$ was $10-90^{\circ}$ at room temperature.

\subsection{Flocculation Tests}

The flocculation test was carried out using cylinder columns for batch cylinder test. $20 \mathrm{wt}$ \% PSFA-Rectorite stock solution was prepared with tap water, then a certain amount of oily wastewater was added into a $100 \mathrm{~mL}$ cylinder column and a certain dosage of flocculant was added into the emulsions immediately. The suspension was shaken by hand for 5 to 8 times. After settling down for ten minutes, the suspension was filtered using a filter cloth to simulate the separation process. Finally, the filtrate was measured for $\mathrm{COD}$ and $\mathrm{pH}$ values. Oil content in wastewater was measured according to the petroleum and natural gas industry standard SY/T 0530-93 of China. The oil in feed and solution after flocculation were extracted by petroleum ether extraction test, and then were analyzed by 721 type spectrophotometer. The COD values were determined by conventional potassium dichromate oxidation process [14].

\section{Results and Discussion}

\subsection{Preparation of PSFA-Rectorite}

A series of different ratios of inorganic polymer and rectorite composite flocculants were prepared, and the effects of reaction temperature and reaction time on yield of polysolicate ferro-aluminum sulfate (PSFA) and rectorite composite were examined. When the ratio is $1: 2$, reaction time is $5 \mathrm{~h}$, and temperature is $50^{\circ} \mathrm{C}$, the yield is $64.58 \%$.

\subsection{The Structure of PSFA-Rectorite}

\subsubsection{FT-IR}

The full FTIR spectra (in the range of $400-4000 \mathrm{~cm}^{-1}$ ) of raw rectorite and rectorite intercalated with PSFA are shown in Figure 2, the broad bands of Ca-rectorite at $3642 \mathrm{~cm}^{-1}$ and $3441.2 \mathrm{~cm}^{-1}$ are due to the $\mathrm{O}-\mathrm{H}$ 


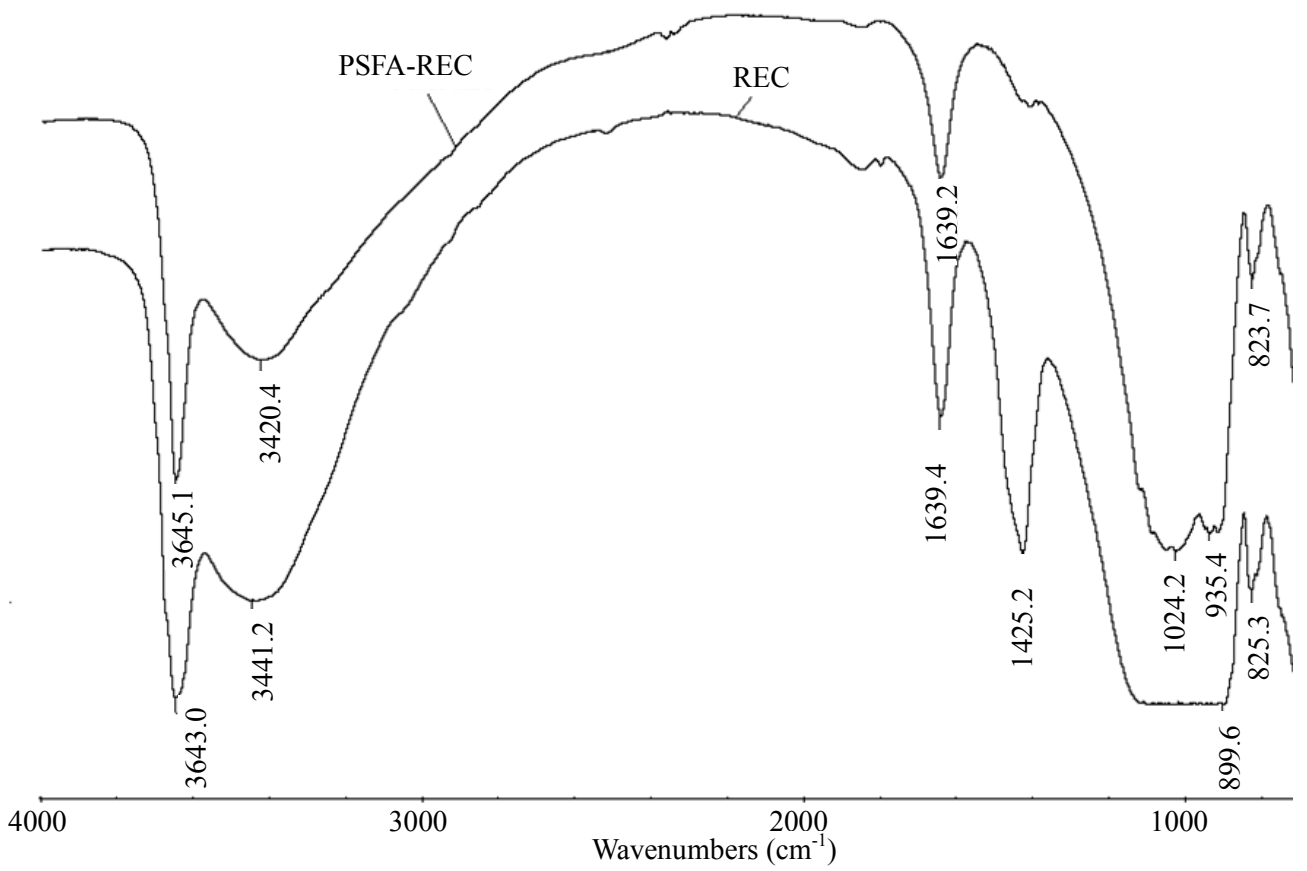

Figure 2. FT-IR spectra of REC and PSFA-REC

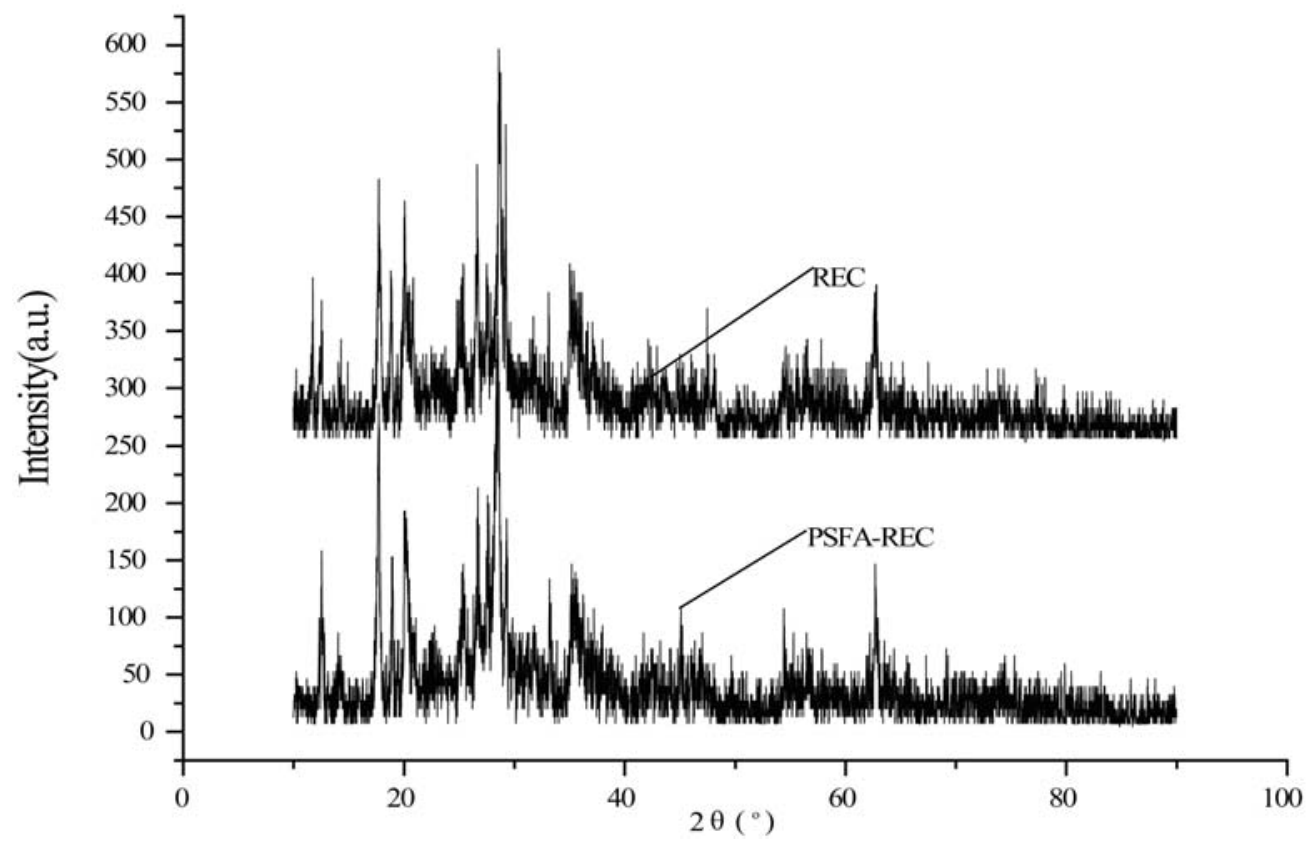

Figure 3. XRD spectra of REC and PSFA-REC

stretching vibration of the silanol $(\mathrm{Si}-\mathrm{OH})$ groups from the solid and $\mathrm{HO}-\mathrm{H}$ vibration of the water molecules adsorbed on the silica surface. The spectral band at 1640 $\mathrm{cm}^{-1}$ reflects bending of the $\mathrm{HO}-\mathrm{H}$ bond of water molecules, which is retained in the silica matrix. The strong band at $1052 \mathrm{~cm}^{-1}$ represents the $\mathrm{Si}-\mathrm{O}$ groups of the tetrahedral sheet. The spectral band at $935.4 \mathrm{~cm}^{-1}$ reflects the stretching vibration of $\mathrm{Al}-\mathrm{O}-(\mathrm{OH})-\mathrm{Al}$. The bands at $695 \mathrm{~cm}^{-1}, 543 \mathrm{~cm}^{-1}$, and $481 \mathrm{~cm}^{-1}$ are due to the deformation and bending modes of the $\mathrm{Si}-\mathrm{O}$ bond $[15,16]$. The appearance of all these peaks demonstrates that the composite PSFA - rectorite had been successfully prepared.

\subsubsection{XRD}

The XRD patterns of the PSFA-rectorite and rectorite 
are shown in Figure 3, the basal spacing was $23.9 \AA$ for Ca-rectorite, $25.7 \AA$ for PSFA-rectorite, which indicates their different structures [17]. It reveals that the PSFA chains have been inserted into the layered silicates and the intercalated composite with larger basal spacing values have formed. The basal spacing of each sample was calculated using Bragg's law:

$$
2 d \sin \theta=n \lambda
$$

where $\mathrm{d}$ is the basal spacing $(\AA)$, the angle of diffraction $\left({ }^{\circ}\right), \lambda$ the wavelength $(\mathrm{nm})$, and $\mathrm{n}$ is the path -difference between the reflected waves which equals an integral number of wavelengths $(\lambda)$. The spacing between layers of the prepared PSFA-rectorite expands because in the process of preparing PSFA-rectorite, other cations entered rectorite interlayer by ion exchange with part of iron, silicon and aluminum ions within rectorite. As suggested in Figure 3, the crystal peak near $20^{\circ}$ in the PSFA/REC gradually disappears and the crystal peak near $28^{\circ}$ becomes wider and weaker as compared to pure REC. It is evident that the addition of PSFA greatly changed the crystallinity of REC. This fact confirms the strong interaction between PSFA and REC as well.

Based on the above analysis, it can be established that PSFA had interacted strongly with clay and was intercalated into the interlayer of clay. In addition, the PSFA chains were sandwiched between the silicate layers while the well ordered multilayer morphology of clay was still present.

\subsection{Application of PSFA-REC}

\subsubsection{The Impact of Different Ratios on the Wastewater Treatment}

As the ratio of rectorite and PSFA is different, the resulting material structure also tends to be different. Similarly, the flocculation capacity on oily wastewater is different when the ratio varies. When the initial oil content is $32 \mathrm{mg} / \mathrm{L}$, the flocculation dosage is $11 \mathrm{mg} / \mathrm{L}$, the performances of flocculants in different ratios on oily wastewater are shown in Table 2.

As can be seen from Table 2, the ratio of rectorite and PSFA has a great impact on the flocculation performance on oily wastewater. When the ratio of PSFA/REC is 2:1,

Table 2. The flocculation effects of different ratio of composite flocculants.

\begin{tabular}{cccc}
\hline Flocculants & oil removal & $\begin{array}{c}\text { COD } \\
\text { removal } \\
(\%)\end{array}$ \\
\hline & $1: 1$ & 75.4 & 71.8 \\
PSFA/REC(m/m) & $1: 2$ & 85.8 & 76.8 \\
& $1: 3$ & 69.8 & 65.6 \\
& $2: 1$ & 87.2 & 92.6 \\
\hline
\end{tabular}

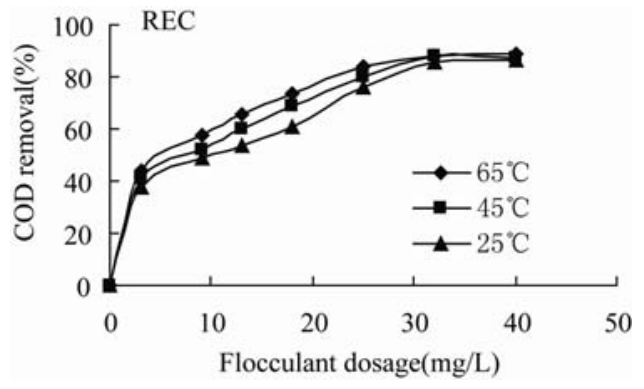

Figure 4. COD removal versus flocculants dosage of REC at different temperatures.

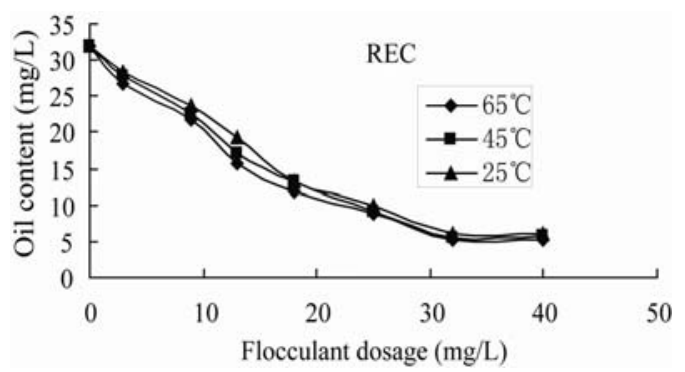

Figure 5. Oily content versus flocculants dosage of REC at different temperatures.

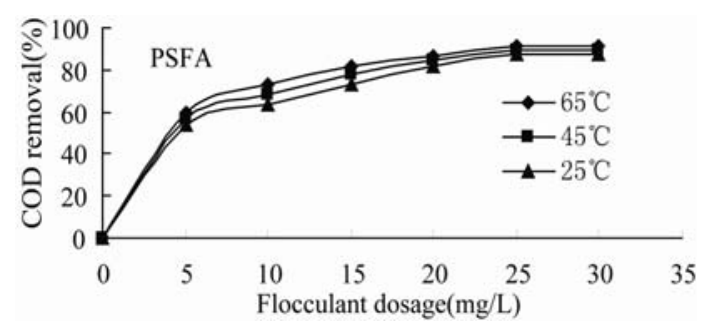

Figure 6. COD removal versus flocculants dosage of PSFA at different temperatures.

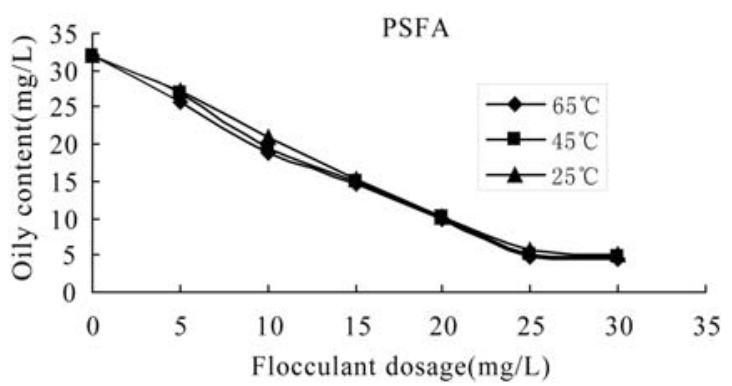

Figure 7. Oily content versus flocculants dosage of PSFA at different temperatures.

the flocculation performance reaches the best.

\subsubsection{Effect of Temperature on the Flocculation Performance}

In order to determine the optimal temperature of the experiment, the effects of temperature on the flocculation performance of PSFA, REC and PSFA/REC (2:1) 
were observed at $25^{\circ} \mathrm{C}, 45^{\circ} \mathrm{C}, 65^{\circ} \mathrm{C}$, respectively.

\subsubsection{Effect of Temperature on the Flocculation Performance of REC}

The flocculation behaviors of wastewater with initial oil content of $32 \mathrm{mg} / \mathrm{L}$ treated by REC were shown in Figures 4-5. The oil removal increased gradually with the increase of flocculant dosage the same temperature. After reaching the maximum value, the oil removal decreased with the increase of REC dosage. In the same flocculant dosage, flocculation efficiency improved significantly with the increase of temperature. Temperature played a very important role on flocculation performance. With the increase of temperature, the required dosage of flocculant to achieve the best performance decreased. Furthermore, at both $25^{\circ} \mathrm{C}$ and $45^{\circ} \mathrm{C}$, flocculation performance was poor and the lowest oil content after treatment were still $6.1 \mathrm{mg} / \mathrm{L}, 5.6 \mathrm{mg} / \mathrm{L}$, which could not meet the WISCO cycle wastewater discharge standard. While at $65^{\circ} \mathrm{C}$, flocculation behavior improved markedly, that is, the maximum oil removal is $83.43 \%$ and the lowest $5.3 \mathrm{mg} / \mathrm{L}$, which could meet the WISCO cycle wastewater discharge standard. The flocculation performances and optimal dosage of flocculant were close at $45^{\circ} \mathrm{C}$ and $65^{\circ} \mathrm{C}$, respectively. Therefore, it was suitable to choose $65^{\circ} \mathrm{C}$, which is closer to on-site temperature, as the treating temperature.

\subsubsection{Effect of Temperature on the Flocculation Performance of PSFA}

Wastewater with initial oil content of $32 \mathrm{mg} / \mathrm{L}$ was treated to remove oil and COD by PSFA, which was shown in Figures 6-7. It can be seen from the figure that at the same temperature, COD removal increased gradually with the increase of flocculant dosage, while the oil removal decreased with the increase of flocculant dosage, and the flocculation behavior achieved the best at $25 \mathrm{mg} / \mathrm{L}$. The result also shows that the higher the temperature is, the better the flocculation performance is, that is, when the temperature is $65^{\circ} \mathrm{C}$, the removal efficiency of COD and oil is the best. In the optimal dosage of $25 \mathrm{mg} / \mathrm{L}$ and temperature of $65^{\circ} \mathrm{C}$, the flocculation efficiency of COD and residual oil content are $91.8 \%$ and $4.7 \mathrm{mg} / \mathrm{L}$, respectively.

\subsubsection{Effect of Temperature on the Flocculation Performance of PSFA-REC}

The flocculation behaviors of wastewater with initial oil content of $32 \mathrm{mg} / \mathrm{L}$ treated by PSFA-REC were shown in Figures 8-9. It can be seen from the figure that the flocculation performance increased with the increase of temperature.

oil content are $89.6 \%$ and $6.8 \mathrm{mg} / \mathrm{L}$, respectively, the

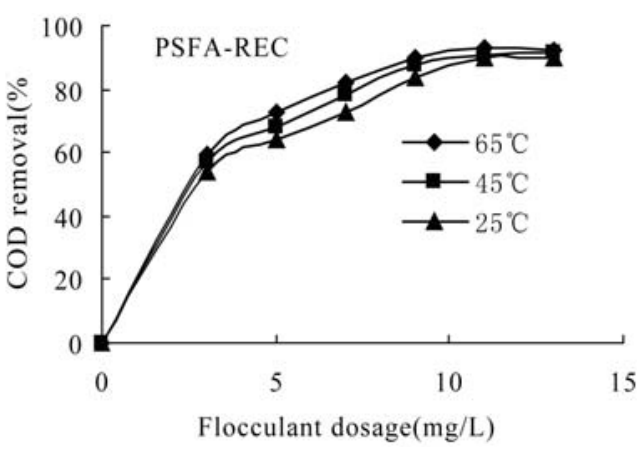

Figure 8. COD removal versus flocculants dosage of PSFA -REC at different temperatures

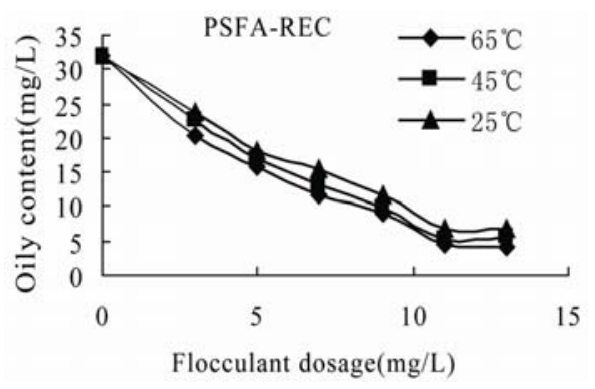

Figure 9. Oily content versus flocculants dosage of PSFA -REC at different temperatures.

flocculation efficiency was not excellent. While at $65^{\circ} \mathrm{C}$, the lowest oil content was $4.1 \mathrm{mg} / \mathrm{L}$ and the highest COD removal efficiency reached $92.6 \%$ after treating by composite PSFA-REC. The experimental result indicates the structural particularity of composite PSFA-REC which made the flocculation performance largely fluctuating and poor repetitiveness. Therefore, freshly prepared PSFA-REC should be used as flocculant to get satisfactory treating effect.

At higher temperature, flocculation occurred quickly after PSFA-REC was added. Compared with the other two flocculants, the composite PSFA-REC was less in dosage, stable and darker. So taking either utility or economy into consideration, the PSFA-REC composite flocculant is ideal.

\subsubsection{The Comparison of Flocculation among Rectorite, PSFA and the Composites of PSFA-Rectorite}

After the flocculation test procedure of rectorite and PSFA alone, the COD and oil content were analyzed to compare with the flocculation performance of the composite PSFA-Rectorite, the results are listed in Table 3. It can be clearly seen from the results that at the same temperature, the dosage of PSFA-Rectorite is smaller than the other two flocculants, but the flocculation performance is better than them, when the temperature is 
Table 3. The Comparison among Rectorite, PSFA and the Composites of PSFA-Rectorite under different temperatures.

\begin{tabular}{|c|c|c|c|c|c|c|c|}
\hline \multirow[t]{3}{*}{ Flocculant } & \multirow[t]{3}{*}{$\begin{array}{l}\text { Dosage } \\
(\mathrm{mg} / \mathrm{L})\end{array}$} & \multicolumn{6}{|c|}{ The flocculation performance under different temperature } \\
\hline & & $25^{\circ} \mathrm{C}$ & & $45^{\circ} \mathrm{C}$ & & $65^{\circ} \mathrm{C}$ & \\
\hline & & $\begin{array}{l}\text { Oil content } \\
(\mathrm{mg} / \mathrm{L})\end{array}$ & $\begin{array}{c}\text { COD removal } \\
(\%)\end{array}$ & $\begin{array}{l}\text { Oil content } \\
(\mathrm{mg} / \mathrm{L})\end{array}$ & $\begin{array}{c}\text { COD } \\
\text { removal (\%) }\end{array}$ & $\begin{array}{l}\text { Oil content } \\
(\mathrm{mg} / \mathrm{L})\end{array}$ & $\begin{array}{c}\text { COD } \\
\text { removal (\%) }\end{array}$ \\
\hline PSFA-REC & 11 & 6.8 & 89.6 & 5.3 & 90.8 & 4.1 & 92.6 \\
\hline PSFA & 25 & 5.7 & 87.2 & 5.2 & 89.1 & 4.7 & 91.8 \\
\hline REC & 32 & 6.1 & 85.6 & 5.6 & 87.8 & 5.3 & 88.3 \\
\hline
\end{tabular}

$65^{\circ} \mathrm{C}$, the flocculation performance of PSFA-Rectorite is the best. That is, the dosage is $11 \mathrm{mg} / \mathrm{L}$, the COD removal efficiency is $92.6 \%$, and the residual oil content is $4.1 \mathrm{mg} / \mathrm{L}(87.2 \%)$.

\subsection{Proposed Mechanism for Wastewater Treatment}

After the flocculant was added at different temperatures, flocculant appeared quickly with its color ivory-white and then became lighter with the flocculants dosages increasing. At $65^{\circ} \mathrm{C}$, when the dosage was less than 25 $\mathrm{mg} / \mathrm{L}$, the flocculant suspended on the surface of wastewater. The volume of flocs was about one tenth of the volume of wastewater. The water was turbid. When the flocculant dosage exceeded the optimal value, flocculation efficiency decreased markedly. In different dosages, flocs were loose, tiny, unstable and easy to disperse even when there was a slight vibration. With the increase of temperature, the suspension decreased markedly.

The influence of temperature on flocculation results is different for organic and inorganic flocculants. The flocculant PSFA and PSFA-REC can react with oil in wastewater because of their positive charge, and the reaction rate increased with the temperature. But the difference is that, on one hand, composite flocculant PSFA-REC is macromolecule with long-chain, its flocculation mechanism is sweeping and bridging, when the temperature is higher, the reaction rate is greater; on the other hand, the molecular weight of inorganic flocculants is lower compared with organic flocculants, the molecular shape cannot weaken the flocculation performance so much that the reaction activity increased with the temperature, which improved the flocculation performance.

The modified rectorite has good performance on oil removal, because rectorite has higher molecular weight, and formed large flocs more easily and quickly, which is good for slurry separation. When it was dispersed in the water, the hydrolyzed polynuclear complexes has high positive charge and large surface area, so that it can quickly adsorb the impurities with negative charge, neutralize the colloidal charge, compress the double layer and lower the colloidal electric potential, therefore, promoting the destabilization, condensation and precipitation of the colloid and suspended substance $[18,19]$. With the increase of dosage, the removal rate of COD and oil increased, but when the dosage goes up to some extent, the surface active sites of the polynuclear hydroxy complex ion will be filled up, which is bad for neutralization, even the excess ion may cause the formed colloidal with positive charge particles re-dispersed in water, thereby reducing the flocculation effect [20].

It can be seen from the flocculation mechanism, the collision among particles will improve the flocculation performance. In a certain concentration, temperature is an important factor which controls collision among particles, high temperature could accelerate the flocculation and improve the performance, while low temperature is bad for the full contact between flocculant and oil, and therefore, is not good for flocculation performance [21-23].

\section{Conclusions}

It can be concluded from the present study that the composite flocculant PSFA-REC was successfully prepared. The technology and process for preparation of the composite is simple. According to the experiment in treating the recycling oily wastewater generated by Wuhan Iron \& Steel Corporation wastewater reservoir, PSFA-REC has better removal efficiency than PSFA or rectorite alone, when the ratio of PSFA and REC is $2: 1$, the flocculation performance reaches the best, besides, the dosage and temperature have great impact on the flocculation performance, when the dosage is $11 \mathrm{mg} / \mathrm{L}$, the temperature is $65^{\circ} \mathrm{C}$, the flocculation behavior of PSFA-REC is the best. The oil content of treated wastewater is less than $5 \mathrm{mg} / \mathrm{L}$, which satisfied the WISCO cycle wastewater discharge standard, the results show that the composite flocculant PSFA-REC is stable 
and convenient to be stored; it's highly feasible and easy to be applied in oily wastewater treatment. It has great perspective in oily wastewater treatment.

\section{Acknowledgements}

We are grateful for the financial support of this research from National Science Foundation of China (20577036, 20777058, 20977070) and National High Technology Research and Development Program (863 Program) (2007AA06Z418) funding.

\section{Reference}

[1] V. Rajakovic and D. Skala, "Separation of Oil-in-Water Emulsions by Freeze/Thaw Method and Microwave Radiation," Separation and Purification Technology, Vol. 49, No. 2, 2006, pp. 192-196. doi:10.1016/i.seppur.2005.09.012

[2] P. Painmanakul, P. Sastaravet, S. Lersjintanakarn and S. Khaodhiar, "Effect of Bubble Hydrodynamic and Chemical Dosage on Treatment of Oily Wastewater by Induced Air Flotation (IAF) Process," Chemical Engineering Research and Design, Vol. 88, No. 5-6, 2010, pp. 693-702. doi:10.1016/i.cherd.2009.10.009

[3] Y. B. Zhou, X. Y.Tang, X. M. Hu, S. Fritschi and J. Lu, "Emulsified Oily Wastewater Treatment Using a Hybrid-Modified Resin and Activated Carbon System," Separation and Purification Technology, Vol. 63, No. 2, 2008, pp. 400-406. doi:10.1016/j.seppur.2008.06.002

[4] M. Perez, R. Rodriguez-Cano, L.I. Romero and D. Sales, "Performance of Anaerobic Thermophilic Fluidized Bed in the Treatment of Cutting-Oil Wastewater," Bioresource Technology, Vol. 98, No. 18, 2007, pp. 3456-3463. doi:10.1016/j.biortech.2006.11.005

[5] M. Masuelli, J. Marchese and N. A. Ochoa, "SPC/PVDF Membranes for Emulsified Oily Wastewater Treatment," Journal of Membrane Science, Vol. 326, No. 2, 2009, pp. 688-693. doi:10.1016/j.memsci.2008.11.011

[6] P. A. Moussas and A. I. Zouboulis, "A New Inorganic-Organic Composite Coagulant, Consisting of Polyferric Sulphate (PFS) and Polyacrylamide (PAA)," Water Research, Vol. 43, No. 14, 2009, pp. 3511-3524. doi:10.1016/j.watres.2009.05.015

[7] S. Suarez, J. M. Lema and F. Omil, "Pre-Treatment of Hospital Wastewater by Coagulation-Flocculation and Flotation," Bioresource Technology, Vol. 100, No. 7, 2009, pp. 2138-2146._doi:10.1016/j.biortech.2008.11.015

[8] E. Guibal and J. Roussy, "Coagulation and Flocculation Of Dye-Containing Solutions Using a Biopolymer (Chitosan), React," Reactive and Functional Polymers, Vol. 67, No. 1, 2007, pp. 33-42. doi:10.1016/i.reactfunctpolym.2006.08.008

[9] A. L. Ahmad and S. W. Puasa, "Reactive Dyes Decolourization Froman Aqueous Solution by Combined Coagulation /Micellar-Enhanced Ultrafiltration Process," Chemical Engineering Journal, Vol. 132, No. 1-3, 2007,

\section{pp. 257-265. doi:10.1016/j.cej.2007.01.005}

[10] M. S. El-Geundi, "Colour Removal from Textile Effluents by Adsorption Techniques," Water Research, Vol. 25, No. 3, 1991, pp. 271-1271.

[11] O. Duman and E. Ayranci, "Adsorptive Removal of Cationic Surfactants from Aqueous Solutions onto High-Area Activated Carbon Cloth Monitored by in Situ UV Spectroscopy," Journal of Hazardous Materials, Vol. 174, No. 1-3, 2010, pp. 359-367. doi:10.1016/j.jhazmat.2009.09.058

[12] T. Shahwan, H. N. Erten and S. Unugur, "A Characterization Study of Some Aspects of the Adsorption of Aqueous $\mathrm{Co}^{2+}$ Ions on a Natural Bentonite Clay," Journal of Colloid and Interface Science, Vol. 300, No. 2, 2006, pp. 447-452. doi:10.1016/j.jcis.2006.04.069

[13] Z. M. Qiu, W. T. Jiang and Z. J. He, "Post-Treatment of Banknote Printing Wastewater Using Polysilicate FerroAluminum Sulfate," Journal of Hazardous Materials, Vol. 166, No. 2-3, 2009, pp. 740-745. doi:10.1016/j.jhazmat.2008.11.128

[14] X. F. Zhao, L. X. Liu and Y. C. Wang, "Influences of Partially Hydrolyzed Polyacrylamide(HPAM) Residue on the Flocculation Behavior of Oily Wastewater Produced from Polymer Flooding," Separation and Purification Technology, Vol. 62, No. 1, 2008, pp.199-204. doi:10.1016/j.seppur.2008.01.019

[15] Z. H. Li, W. T. Jiang and H. L. Hong, “An FTIR Investigation of Hexadecyltrimethyl Ammonium Intercalation into Rectorite," Spectrochimica Acta Part A: Molecular and Biomolecular Spectroscopy, Vol. 71, No. 4, 2008, pp. 1525-1534. doi:10.1016/j.saa.2008.05.015

[16] F. Ayari, E. Srasra and M. Trabelsi-Ayadi, "Characterization of Bentonitic Clays and Their Use as Adsorbent," Desalination, Vol. 185, No. 1-3, 2005, pp. 391-397. doi:10.1016/j.desal.2005.04.046

[17] S. M. Yu, C. L. Chen, P. P. Chang, T. T. Wang, S. S. Lu and X. K. Wang, "Adsorption of Th (IV) onto Al-Pillared Rectorite: Effect of $\mathrm{pH}$, Ionic Strength, Temperature, Soil Humic Acid and Fulvic Acid," Applied Clay Science, Vol. 38, No. 3-4, 2008, pp. 219 -226. doi:10.1016/j.clay.2007.03.008

[18] E. I. Unuabonah, B. I. Olu-Owolabi, K. O. Adebowale and A. E. Ofomaj, "Adsorption of Lead and Cadmium Ions from Aqueous Solutions by TripolyphosphateImpregnated Kaolinite Clay," Colloids and Surfaces A: Physicochemical and Engineering Aspects, Vol. 292, No. 2-3, 2007, pp. 202-211. doi:10.1016/j.colsurfa.2006.06.024

[19] N. Kudo and Y. Kawashima, "Fish Oil-Feeding Prevents Perfluorooctanoic Acid Induced Fatty Liver in Mice," Toxicology and Applied Pharmacology, Vol. 145, No. 2, 1997, pp. 285-293. doi:10.1006/taap.1997.8186

[20] S. Wen, Y. Peng and X. E. Lee, "Coagulation of Panicles through Rapid Mixing," Drying Technology, Vol. 24, No. 10, 2006, pp. 1271-1276.

[21] A. Lerch, S. Panglisch, P. Bucht, Y. Tomit, H. Yonekaw, K. Hattori and R. Gimbel, "Direct River Water Treatment 
Using Coagulation/Ceramic Membrane Microfiltration," Desalination, Vol. 179, No. 1-3, 2005, pp. 41-50. doi:10.1016/j.desal.2004.11.054

[22] P. Mpofu, J. Addai-Mensah and J. Ralston, "Temperature Influence of Nonionic Polyethylene Oxide and Anionic Polyacrylamide on Flocculation and Dewatering Behavior of Kaolinite Dispersions," Journal of Colloid and
Interface Science, Vol. 271, No. 1, 2004, pp. 145-156. doi:10.1016/j.jcis.2003.09.042

[23] E. Arinaitwe and Marek Pawlik, "A Method for Measuring the Degree of Anionicity of Polyacrylamide-Based Flocculants," International Journal of Mineral Processing, Vol. 91, No. 1-2, 2009, pp. 50-54.

doi:10.1016/j.minpro.2008.12.002 